\title{
IDADES Rb-Sr DAS ROCHAS DA REGIÃO DE BANANAL - SP
}

\author{
C.M.Dias Neto, C.C.G.Tassinari, M.Egydio Silva
}

PALAVRAS-CHAVE: geocronologia, método Rb-Sr, evolução geológica.

DLAS NETO, C.M. et al. (1995) Idades Rb-Sr das rochas da regiào de Bananal - SP. Bol.JG-USP, Ser.Cient., 26:59-68.

\section{RESUMO}

Este trabalho apresenta novos dados geocronológicos $\mathrm{Rb}-\mathrm{Sr}$, em rocha total, dos principais tipos litológicos da regiåo limítrofe dos estados de Săo Paulo e Rio de Janeiro, no contexto da Serra do Mar, com o objetivo de caracterizar a seqüência de eventos geológicos e as possiveis relaçōes entre as rochas presentes.

Os paragnaisses, predominantes na regiāo, os núcleos ortognaissicos, considerados como embasamento da sequéncia paraderivada, e os leucogranitos, injetados em ambos, forneceram diagramas isocrônicos que convergem para uma época ao redor de $700 \mathrm{Ma}$, interpretada como o processo metamórfico gerador das rochas gnáissicas, o qual também propiciou, através de fusão parcial, a formaçăo dos leucogranitos. A proximidade dos pontos relativos a estas litologias, no diagrama de evoluçä̀o do $\mathrm{Sr}$, reforça esta consideraçâo.

Como representante dos granitos ambientados tectonicamente $\mathrm{em}$ expressivas zonas de cisalhamento dúcteis, relativamente comuns na regiảo, o granito Getulândia, analisado radiometricamente, forneceu a idade de $514 \mathrm{Ma}$, se enquadrando entre os corpos graníticos tardi-tectônicos relacionados ao Ciclo Brasiliano tardio, que se estendeu até o Cambriano Médio.

\section{ABSTRACT}

New $\mathrm{Rb} / \mathrm{Sr}$ whole rock isochron ages have been determined for the main lithologica: units that occur in Salo Paulo and Rio de Janeiro States. These rocks belong to the "Serra do Mar" domain The purpose of this work is to characterize the sequence of the geological events as well as the possible relationship between the different rocks.

The geochronological data suggest that the paragneisses and the basement rocks, represented by orthogneiss nuclei, were generated under amphibolite conditions around $700 \mathrm{Ma}$. At the same time the leucogranites were generated by partial melting processes and injected into both gneiss types.

Tarditectonic granitic magmatic activities took place within ductile shear zones. One of the granites, the Getulandia granite, yielded an age of $514 \mathrm{Ma}$, falling in the range of the late Brasiliano Cycle which extended into the Middle Cambrian.

\section{INTRODUÇĀO}

A região de Barra Mansa (RJ) Bananal (SP), localizada, sob o ponto de vista tectônico, na porção central da Faixa de Dobramentos Ribeira (Cordani \&

Departamento de Geologia Geral, Instituto de Geociéncias/USP, Săo Paulo, Brasil. 
Brito Neves, 1982), no contexto da Serra do Mar (Fig. 1), tem sido motivo de controvérsias em relação às unidades geológicas e estruturas presentes. As rochas da área são atribuídas, segundo trabalhos regionais, ao Grupo Paraíba (Ebert, 1968) ou ao Complexo Embu (Hasui et al., 1982).

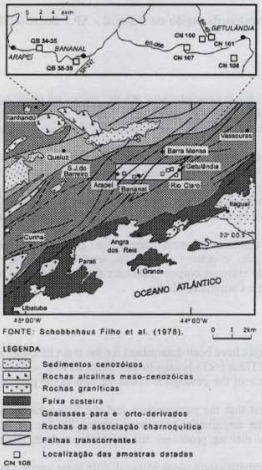

Figura 1-Mapa gcológico simplificado com a localização da área de estudo e das amostras datadas.

O Complexo Embu (Hasui, 1975) foi definido na região sudeste do Estado de São Paulo, com direção NE-SW, sendo, litologicamente, representado por xistos e migmatitos com paleossoma xistoso e, subordinadamente, quartzitos, dolomitos e anfibolitos (Hasui \& Sa- dowski, 1976).

De uma forma geral, o metamorfismo nestas rochas é da fácies anfibolito, sendo que nos ectinitos ocorrem transiçôes entre as fácies xisto verde e anfibolito, com evidências de retrometamorfismo.

Os dados geocronológicos mais significativos neste complexo indicam uma época entre 2.700 e 2.500 Ma para a formação dos primeiros fragmentos de crosta continental, que sofreram intensa migmatização durante o Mesoproterozóico, em torno de $1.400 \mathrm{Ma}$ e também foram afetados por granitizações durante o Ciclo Brasiliano por volta de 600 $550 \mathrm{Ma}$ (Tassinari, 1988; Babinski, 1988).

Os trabalhos de Rosier (1957, $1965)$ e de Ebert $(1956,1957,1968$, 1971) na região limítrofe dos estados de Minas Gerais, Rio de Janeiro e São Paulo, permitiram a caracterizaçăo do que foi chamado na época Série (Grupo) Paraiba. Hasui et al. (1982), em trabalho de sintese regional, restringiram a ocorrência do, então designado, Complexo Paraíba do Sul, praticamente ao Estado de São Paulo, figurando em seu lugar, no Estado do Rio de Janeiro, o Complexo Embu. Entretanto, trabalhos de detalhe posteriores (Machado, 1984; Heilbron, 1993) continuaram identificando as rochas presentes no setor ocidental do Estado do Rio de Janeiro como pertencentes ao Complexo Paraiba do Sul. Este complexo é constituído, predominantemente, por gnaisses e migmatitos, com paleossoma gnáissico, granulítico, anfibolítico ou xistoso. Intercalações de mármores, rochas calciossilicáticas, xistos feldspáticos e metabasitos são frequientes (Hasui \& Oliveira, 1984). Núcleos granulíticos, assim como corpos graníticos, também ocorrem neste complexo (Cavalcante et al., 1979).

Chaves (1983), ao enfocar um segmento da área em questão, opta por 
apresentar, no aspecto regional, a geologia do Estado de São Paulo em separado daquela do Rio de Janeiro, pois os conteúdos dos dois levantamentos básicos não permitem uma integração. Estudos desenvolvidos no Estado de São Paulo (Fernandes, 1991) ou enfocados a partir deste (Hasui \& Oliveira, 1984) designam a seqüência de rochas paraderivadas, predominantes na área, como Complexo Embu, enquanto os trabalhos elaborados a partir do Estado do Rio de Janeiro (Heilbron et al., 1991; Machado, 1984) atribuem à sequência paraderivada a denominação Complexo Paraíba do Sul. Até o momento, não está satisfatoriamente estabelecido se ocorrem dois complexos justapostos pelas grandes zonas de cisalhamento, presentes na área, ou se a mesma seqüência de rochas recebe as duas denominações.

Os poucos trabalhos geocronológicos, com caráter regional, existentes (Cordani \& Teixeira, 1979; Tassinari, 1988; Tassinari \& Campos Neto, 1988; Babinski, 1988) não permitem extrapolações em função da complexidade geológica da região.

Este trabalho apresenta novos dados geocronológicos $\mathrm{Rb}-\mathrm{Sr}$, em rocha total, dos principais tipos litológicos da área em questão, com o objetivo de caracterizar a seqüência de eventos geológicos e as possíveis relações entre as unidades geológicas presentes.

\section{CONTEXTO GEOLÓGICO}

Basicamente, na área em questão, predominam rochas gnáissicas paraderivadas, essencialmente xistosas, com quartzitos, anfibolitos, cálcio-silicáticas, gonditos e mármores subordinados. Os paragnaisses, ricos $\mathrm{cm}$ biotita, apesar de heterogêneos, normalmente se apresentam bandados, com niveis quartzofeldspáticos, onde predomina microclinio, e bandas ricas em biotita, por vezes com homblenda. A presença de zircão, apatita e granada é relativamente comum, podendo ainda ocorrer sillimanita, muscovita e turmalina, localmente.

Núcleos de ortognaisses, de composição granodiorítica, sāo interpretados como o embasamento da sequiência metassedimentar, em concordância com o que Machado (1984) propõe para a região de Valença - Vassouras (RJ). Estes se apresentam relativamente homogêneos, com estrutura bandada fina, centimétrica a milimétrica, de forma geral, com níveis quartzo-feldspáticos, onde microclínios e plagioclásios se alternam em predomínio, e níveis ricos em biotitas e homblendas, sendo as primeiras produto de alteração das segundas por retrometamorfismo. Como acessórios sāo comuns zircão, apatita e titanita.

Os mesmos padrões de redobramento e estruturas Ss e Sc que ocorrem nos paragnaisses estão presentes também nos corpos ortoderivados. Isto sugere que estes corpos ou não apresentavam estruturas anteriores, ou estas teriam sido obliteradas durante o processo de gnaissificação regional, que afetou a área no Evento Brasiliano.

Ocorrem ainda vários pequenos corpos graníticos foliados e concordantes com os paragnaisses, cujos contatos gradacionais e composição mineralógica sugerem, como origem, fusões parciais localizadas durante o processo de gnaissificação. Esses corpos possuem formas alongadas, acompanhando as fortes orientações interiores, assim como o marcante trend regional NE-SW impresso nas rochas orto e paraderivadas.

Sills de leucogranitos orientados, com espessuras decimétricas a decamétricas, associados aos para e ortognaisses, são relativamente comuns. Petrograficamente, o microclínio é predominante e secundariamente quartzo, zircăo e apatita, com biotitas ocorrendo, preferencialmente, próximas ao contato com as encaixantes. Granadas são encontra- 
das com facilidade, enquanto turmalinas são raras.

Potentes zonas anastomosadas de cisalhamento dúctil verticalizadas, orientadas entre N20-80E, em função de suas características fortemente sinuosas, afetam toda a área, produzindo arrastes e reorientações das estruturas metamórficas anteriores, cujos mergulhos, fracos a moderados, se verticalizam no interior das zonas de cisalhamento. Não foram observados truncamentos entre as estruturas gnáissicas e aquelas verticalizadas, havendo uma passagem gradual entre elas, o que sugere um processo de deformação progressiva. Predominam movimentos dextrais, entretanto, nâo raramente, são encontrados indicadores cinemáticos indicando regime sinistral, também com caráter dúctil.

Expressivos corpos graníticos, sin a tardi-cisalhamento dúctil estão presentes, normalmente associados, ou mesmo obliterando, as maiores zonas de falhas. Suas formas alongadas na orientação regional NE-SW, assim como suas orientações internas, no mínimo nas bordas, concordantes com aquelas presentes nas encaixantes, reforçam esta associação. Esta granitogênese, de caráter calcioalcalino do tipo Cordilheirano (Figueiredo \& Campos Neto, 1993), ocorreu entre 550 e $500 \mathrm{Ma}$, estando relacionada ao Ciclo Brasiliano tardio, caracterizado como um evento curto e jovem, que se iniciou ao redor de $600 \mathrm{Ma}$ e terminou no Cambriano Médio, 540$530 \mathrm{Ma}$. Este evento foi reconhecido por Trompette (1994) nas faixas que ocupam a borda oeste do Gondwana Ocidental e interpretado por Campos Neto \& Figueiredo (1995) como uma nova fase orogenética denominada de Rio Doce.

\section{METODOLOGIA Rb-Sr}

As análises isotópicas deste trabalho foram realizadas nos laboratórios do Centro de Pesquisas Geocronológicas do Instituto de Geociências da Universidade de São Paulo.

As amostras foram inicialmente britadas e pulverizadas, sendo que os teores de $\mathrm{Rb}$ e $\mathrm{Sr}$ foram determinados por análises de fluorescência de raios-X. Para as amostras com baixos ou altos valores de $\mathrm{Rb}$ e $\mathrm{Sr}(<50 \mathrm{ppm}$ e $>500$ ppm), os teores foram determinados por técnicas de diluição isotópica, utilizando-se padrōes de ${ }^{85} \mathrm{Rb}$ e ${ }^{84} \mathrm{Sr}$, conforme Kawashita (1972).

As amostras foram atacadas com $\mathrm{HF}+\mathrm{HNO}_{3}$ por uma noite, a $65^{\circ} \mathrm{C}$, e o Sr foi separado, utilizando-se uma coluna convencional de troca iônica com resina de troca catiônica AG50WX8 $(200-400 \#)$, como descrito por Kawashita (1972).

As análises isotópicas de $\mathrm{Sr}$ foram efetuadas por espectrômetro de massa automatizado VGISOMASS 354 . O Sr foi depositado com ácido fosfórico em um filamento simples de $\mathrm{Ta}$. As razōes de ${ }^{87} \mathrm{Sr} / 86 \mathrm{Sr}$ foram corrigidas por fracionamento de massa através da normalização com o valor de 0,1194 para a relação ${ }^{86} \mathrm{Sr} / 88 \mathrm{Sr}$.

Durante o periodo de execução das análises deste trabalho, os valores medidos para o padrāo NBS-987 foram de $0,71026 \pm 0,00002$. Os testes de branco para o $\mathrm{Sr}$ foram da ordem de $2 \mathrm{pg}$. As idades Rb-Sr foram calculadas utilizando-se a constante de decaimento $\lambda_{\mathrm{Rb}}=$ $1,42 \times 10^{-11}$ anos $^{-1}$, conforme recomendação de Steiger \& Jäger (1978) e os erros considerados são $1 \sigma$.

\section{DISCUSSĀO E APRESENTAÇĀO DOS DADOS GEOCRONOLOGI- $\cos$}

Foram realizadas 25 análises $\mathrm{Rb}$ $\mathrm{Sr}$ em rocha total (Tabela 1) em amostras das principais unidades litológicas presentes na área, estando representados os núcleos ortognáissicos de composi- 
Tabela 1 - Dados analíticos Rb-Sr - Rocha Total.

\begin{tabular}{|c|c|c|c|c|c|c|c|}
\hline $2^{\circ}$ campo & rocha & coordenada & Rb ppm & Sr ppm & ${ }^{87} \mathrm{Rb} /{ }^{85} \mathrm{Sr}$ & ${ }^{87} \mathrm{Sr} / 86 \mathrm{Sr}$ & $\mathrm{n}^{\circ} \mathrm{lab}$ \\
\hline $\mathrm{Cn} 100 \mathrm{~A}$ & ortogn & $22^{\circ} 40^{\prime}-44^{\circ} 09^{\prime}$ & 211.9 & 595.3 & $1.0320 \pm 0.0290$ & $.72290 \pm 0.00013$ & 11534 \\
\hline CnlooC & ortogn & $22^{\circ} 40^{\circ}-44^{\circ} 09^{\prime}$ & 254.7 & 537.9 & $1.3730 \pm 0.0390$ & $0.72478 \pm 0.00007$ & 11535 \\
\hline Cnl00 I & ortogn & $22^{\circ} 40^{\prime}-44^{\circ} 09^{\prime}$ & 182.6 & 663.7 & $0.7970 \pm 0.0230$ & $0.72088 \pm 0.00006$ & 11536 \\
\hline Cn107 D & ortogn & $22^{\circ} 41^{\prime}-44^{\circ} 10^{\prime}$ & 234.0 & 395.5 & $1.7160 \pm 0.0480$ & $0.73024 \pm 0.00011$ & 11538 \\
\hline Cnl01Al & leucogr & $22^{\circ} 3$ & 296.3 & 350.6 & 0690 & $0.73513 \pm$ & 1697 \\
\hline Cn101A2 & leucogr & $22^{\circ} 39^{\prime}$ & 318.9 & 122.4 & $7.5970 \pm 0.2130$ & $0.78363 \pm 0.00006$ & 11698 \\
\hline Cn101B1 & leucogr & $22^{\circ} 39^{\prime}-44^{\circ} 09^{\prime}$ & 288.0 & 170.8 & $4.9070 \pm 0.1380$ & $0.76452 \pm 0.00006$ & 11699 \\
\hline CnI00 J & leucogr & $22^{\circ} 40$ & 137.6 & 912.6 & .0061 & $0.71669 \pm 0.6$ & 11700 \\
\hline Cn108 F & granito & $22^{\circ}$ & 1.8 & 63.8 & 323 & .797 & 539 \\
\hline Cn108 G & granito & $22^{\circ} 41^{\prime}-44^{\circ} 06^{\prime}$ & 9.3 & 58.1 & $10.5150 \pm$ & $0.79402+$ & 818 \\
\hline Cnlos K & granito & $22^{\circ} 41^{\prime}-44^{\circ} 06^{\prime}$ & 5.8 & 78.8 & $7.9800 \pm 0.2240$ & 0.77731 & 11540 \\
\hline Cn108 L & granito & $22^{\circ} 41^{\prime}$ & 254.4 & 185.5 & 3.98 & 0.741 & 11541 \\
\hline Cal08NI & granito & $22^{\circ} 41^{\prime}-44^{\circ} 06^{\prime}$ & 118.9 & 382.4 & 250 & 0.714 & 11542 \\
\hline Cn108N2 & granito & $22^{\circ} 41^{\prime}-44^{\circ} 06^{\prime}$ & 88.8 & 419.2 & 170 & $0.71167 \pm$ & 12819 \\
\hline $\mathrm{Cn} 108 \mathrm{O} 2$ & granito & $22^{\circ} 41^{\prime}-44^{\circ} 06$ & $30.70^{*}$ & $283.90^{4}$ & 0.313 & 0.708 & 11543 \\
\hline QB 34A & paragn & $22^{\circ} 40^{\prime}-44^{\circ} 25^{\prime}$ & 63.0 & 132.7 & 1.3780 & 0.73710 & 11828 \\
\hline QB 34 B & paragn & $22^{\circ} 40^{\prime}-44^{\circ} 25^{\prime}$ & 212.3 & 112.3 & $5.5090 \pm 0.1550$ & $0.77746 \pm 0.00005$ & 11829 \\
\hline $\mathrm{QB} 34 \mathrm{C}$ & paragn & $22^{\circ} 40^{\prime}-44^{\circ} 25^{\prime}$ & 187.0 & 138.0 & $3.9450 \pm 0.1110$ & $0.76820 \pm 0.00007$ & 11830 \\
\hline QB 34 E & paragn & $22^{\circ} 40^{\prime}-44^{\circ} 25^{\prime}$ & 230.0 & 145.0 & 1300 & $0.76393 \pm 0.0$ & 11831 \\
\hline $\mathrm{QB} 35 \mathrm{~A}$ & paragn & $22^{\circ} 40^{\prime}-44^{\circ} 25^{\prime}$ & 174.0 & 296.0 & $1.7060 \pm 0.0480$ & $0.73721 \pm 0.00006$ & 11833 \\
\hline $\mathrm{QB} 38 \mathrm{~A}$ & paragn & $22^{\circ} 40^{\circ}-44^{\circ} 22^{\prime}$ & 113.0 & 336.0 & $0.9750 \pm 0.0280$ & $0.72089 \pm 0.00011$ & 11849 \\
\hline $\mathrm{QB} 38 \mathrm{E}$ & paragn & $22^{\circ} 40^{\prime}-44^{\circ} 22^{\prime}$ & 99.0 & 212.0 & $1.3540 \pm 0.0380$ & $0.72431 \pm 0.00009$ & 11850 \\
\hline QB 38F & paragn & $22^{\circ} 40^{\circ}-44^{\circ} 22^{\prime}$ & 149.0 & 196.7 & $2.1970 \pm 0.0620$ & $0.73065 \pm 0.00006$ & 11851 \\
\hline QB 39 C & paragn & $22^{\circ} 40^{\prime}-44^{\circ} 22^{\prime}$ & 121.0 & 125.0 & $2.8110 \pm 0.0790$ & $0.74113 \pm 0.00009$ & 11853 \\
\hline QB $39 \mathrm{G}$ & paragn & $22^{\circ} 40^{\circ}-44^{\circ} 22^{\prime}$ & 163.0 & 92.0 & $5.1570 \pm 0.1450$ & $0.76620 \pm 0.00010$ & 11854 \\
\hline
\end{tabular}

*análises por diluição isotópica.

ção monzogranítica a granodiorítica, os paragnaisses predominantes na área, os leucogranitos foliados associados às rochas para e ortoderivadas e um dos corpos graníticos tardi-cinemáticos encaixados em expressiva zona de cisalhamento dúctil. A localização das amostras datadas está representada na Figura 1.

Cinco amostras relativas aos ortognaisses, quando lançadas em um diagrama isocrônico $\mathrm{Rb}-\mathrm{Sr}$, definem uma reta com inclinação relativa à idade de $668 \pm 36 \mathrm{Ma}$, com uma razão ${ }^{87} \mathrm{Sr} / 86 \mathrm{Sr}$ inicial de $0,7130 \pm 0,0006$ e um valor de MSWD de 8,5 (Fig. 2). Os leucogranitos, de composição granítica a quart-

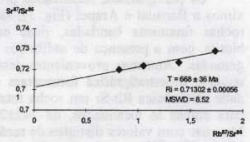

Figura 2 - Diagrama isocrónico $\mathrm{Rb} / \mathrm{Sr}$ dos ortognaisses.

zosienítica, presentes em forma de sills no interior dos ortognaisses, apresentaram em diagrama isocrônico $\mathrm{Rb}-\mathrm{Sr}$ uma idade de $688 \pm 13 \mathrm{Ma}$, com razão isotópica inicial ${ }^{87} \mathrm{Sr}^{\prime 86} \mathrm{Sr}$ de $0,7124 \pm$ 
0,0001, e um valor de MSWD de 7,5

(Fig. 3). Como os ortognaisses analisados apresentam fortes injeções de material quartzofeldspático, relacionadas a estes leucogranitos, e constatando-se que tanto as idades obtidas, como os valores das razões iniciais de $\mathrm{Sr}$ são coincidentes, dentro dos erros analíticos, interpretamos as idades próximas a 680 $\mathrm{Ma}$ como a época de formação dos leucogranitos, a qual representaria um estágio terminal do evento metamórfico responsável pela geraçāo dos ortognaisses. Os elevados valores das relações ${ }^{87} \mathrm{Sr} / 86 \mathrm{Sr}$ iniciais indicam que os magmas parentais dos granitóides foram gerados a partir de processos de fusão parcial principalmente dos ortognaisses.

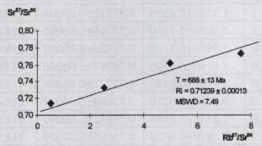

Figura 3 - Diagrama isocrónico $\mathrm{Rb} / \mathrm{Sr}$ dos leucogranitos.

Os paragnaisses, localizados próximos a Bananal e Arapei (Fig. 1), são rochas finamente bandadas, ricas em biotita, com a presença de anfibólios e granadas. Amostras provenientes desta unidade litoestratigráfica forneceram idade errocrónica $\mathrm{Rb}-\mathrm{Sr}$ em rocha total, para ambas as localidades, de $742 \pm 20$ $\mathrm{Ma}$, mas com valores distintos de razão inicial ${ }^{87} \mathrm{Sr} / 86 \mathrm{Sr}$, sendo para Bananal $0,7211 \pm 0,0006$ e para Arapeí 0,7101士 0,0005 (Figs. 4 e 5). Esta variação de razões iniciais deve-se, possivelmente, à heterogeneidade do material sedimentar, com memórias isotópicas distintas, que deu origem às rochas gnáissicas durante o processo metamórfico. O elevado valor calculado para o MSWD das amos-

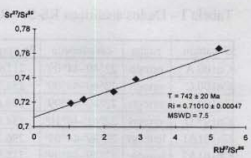

Figura 4 - Diagrama isocrônico Rb/Sr dos paragnaisses Bananal.

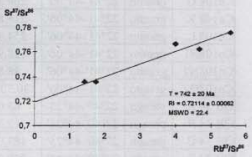

Figura 5 - Diagrama isocrónico $\mathrm{Rb} / \mathrm{Sr}$ dos paragnaisses Arapeí.

tras próximas a Arapei sugerem que as amostras consideradas não foram completamente homogeneizadas isotopicamente. As idades entre 750 e $700 \mathrm{Ma}$, muitas vezes obtidas através de errócronas, já são uma constante nas rochas pré-cambrianas do Estado de São Paulo, principalmente no âmbito do denominado Domínio Embu (Tassinari, 1988), e parecem definir um importante evento metamórfico, que teria causado não só a geração de diversos tipos de paragnaisses, como também processos de fusōes parciais que teriam produzido uma grande quantidade de granitos de anatexia. Este evento, ainda não claramente definido geocronologicamente, poderia englobar o episódio gerador dos leucogranitos, ao redor de $680 \mathrm{Ma}$, caracterizado anteriormente.

Os paragnaisses e as rochas do embasamento se encontravam em profundidades distintas, no interior da cros- 
ta, durante o processo metamórfico. As grandes zonas de cisalhamento, presentes na área, deslocaram significativamente estas rochas de suas posiçōes originais, colocando-as, atualmente, lado a lado. Desta forma é possivel explicar as diferenças de idades entre estas rochas em função do fechamento do sistema $\mathrm{Rb}-\mathrm{Sr} \mathrm{cm}$ materiais mais profundos ocorrer tardiamente em relação à supraestrutura.

$O$ Granito Getulândia, ambientado tectonicamente em expressiva zona de cisalhamento dúctil, obliterando-a localmente, foi objeto de amostragem sistemática neste trabalho, tendo sido analisadas 7 amostras. Deste conjunto, 4 representam o corpo em si, de composição granítica, com predomínio de microclinio e secundariamente quartzo, plagioclásio e biotitas, estas últimas geradas por alteração de hormblendas. Como acessórios são comuns zircão, apatita, titanita e alanita. As 3 restantes representam encraves máficos, que ocorrem em dimensões centimétricas até métricas, possuindo composiçâo monzonítica a monzogábrica. Predominam plagioclásios e anfibólios, estes gerados a partir de reações de alteração de ortopiroxênios (hiperstênio) presentes. Zircão, apatita e titanita são acessórios comuns.

Inicialmente estas amostras foram tratadas conjuntamente, com 4 pontos graníticos e 3 referentes aos encraves máficos (Fig. 6). O diagrama isocrôni-

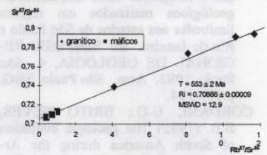

Figura 6 - Diagrama Rb/Sr do Granito Getulândia com enclaves máficos. co indicou a idade de $553 \pm 2 \mathrm{Ma}$, com razão inicial de $0,7066 \pm 0,0001$. O valor de 12,8 do MSWD para a reta traçada e a conseqüente não colinearidade dos pontos analíticos no diagrama isocrônico, sugerem que os enclaves não estavam homogeneizados isotopicamente com o granitóide. Neste sentido os pontos relativos aos encraves e ao granitóide foram tratados em separado. Os pontos analíticos relativos aos encraves máficos, forneceram uma isócrona com a idade de $685 \pm 31 \mathrm{Ma}$ e com razão inicial ${ }^{87} \mathrm{Sr}^{86} \mathrm{Sr}$ de $0,7057 \pm 0,0002$ (Fig. $7)$, enquanto que os pontos relativos ao material granítico, indicaram a idade de $514 \pm 8 \mathrm{Ma}$, com razão inicial de 0,7129 \pm 0.0012 (Fig. 8). Esta idade é próxima das idades U-Pb em monazitas $(528 \pm 1$ $535 \pm 1 \mathrm{Ma}$ ), apresentadas para a intrusão deste corpo por Valladares et al. (1995). Portanto, neste trabalho consideramos a idade $514 \mathrm{Ma}$ como a época do fecha-

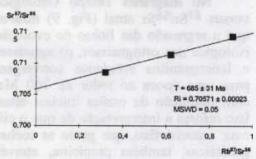

Figura 7 - Diagrama isocrônico $\mathrm{Rb} / \mathrm{Sr}$ dos enclaves máficos do Granito Getulândia.

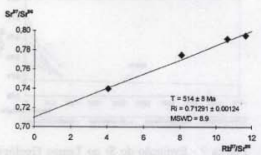

Figura 8 - Diagrama isocrônico $\mathrm{Rb} / \mathrm{Sr}$ do Granito Getulândia. 
mento do sistema $\mathrm{Rb}-\mathrm{Sr}$ durante o processo de formacão do granito de Getulândia. Com relação aos encraves, é muito provável que aquela idade reflita o processo metamórfico que afetou as rochas encaixantes, datado nos orto e paragnaisses, tratando-se, desta forma, de xenólitos, alçados pelo emplacement do granito, e não homogeneizados isotopicamente em função de suas dimensões métricas.

\section{CONSIDERAÇÕES FINAIS}

A partir dos dados geocronológicos apresentados neste trabalho, podemos considerar que as rochas metamórficas da área em estudo formaram-se no Neoproterozóico, dentro de um evento geodinâmico, onde os processos de retrabalhamento crustal predominaram largamente sobre os processos de acresção continental.

No diagrama Tempo Geológico versus ${ }^{87} \mathrm{Sr} / 86 \mathrm{Sr}$ atual (Fig. 9) nota-se que a regressão das linhas de evolução isotópica dos ortognaisses, paragnaisses e leucogranitos estudados convergem para uma época ao redor de $700 \mathrm{Ma}$, com definição de razões iniciais altas. Isto reforça a interpretação de que o climax metamórfico, que gerou as rochas gnáissicas, também propiciou, através de processos de fusâo parcial, a formaçâo dos leucogranitos.

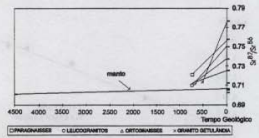

Figura 9 - Evolugão do Sr no Tempo Geológico.
Cabe ressaltar que corpos graníti$\cos$ do tipo $\mathrm{S}$, muitos deles portadores de duas micas, aparentemente formaram-se contemporaneamente ao evento geodinâmico ( $700 \mathrm{Ma})$, determinado na área deste estudo. Tal inferência é reforçada pelo corpo da Serra do Quebra Cangalha, pouco a sul da área em questão, que apresenta idade $\mathrm{Rb}-\mathrm{Sr}$ isocrônica em rocha total de $713 \pm 43 \mathrm{Ma}$ e razão inicial $87 \mathrm{Sr} / 86 \mathrm{Sr}$ de $0,726 \pm 0,002$ (Tassinari, 1988).

\section{REFERÊNCIAS BIBLIOGRÁFICAS}

BABINSKI, M. (1988) Metodologia isotópica $\mathrm{Pb} / \mathrm{Pb}$. Aplicação aos migmatitos e rochas associadas da regiāo de São José dos Campos, São Paulo, 101p. (Dissertação Mestrado) - IPEN.

CAMPOS NETO, M.C.; FIGUEIREDO, M.C.H. (1995) The Rio Doce Orogeny, Southeastern Brazil. Journal of South American Earth Sciences, v.8, n.2, p.143-162.

CAVALCANTE, J.C.; CUNHA, H.C. S.; CHIEREGATI, L.A.; KAEFER, L.Q.; ROCHA, J.M.; DAITX, E.C.; COUTINHO, M.G.N.; YAMAMOTO, K.; DRUMOND, J.B.V.; ROSA, D.B.; RAMALHO, R. (1979) Projeto Sapucai. Brasilia, DNPM/ CPRM. 299p. (seção Geologia Básica, n.2).

CHAVES, M.L.S.C. (1983) Contribuição à integração entre mapeamentos geológicos realizados em regiôes limitrofes aos estados de São Paulo e Rio de Janeiro. In: SIMPÓSIO REGIONAL DE GEOLOGIA, 4, São Paulo, 1983. Atas. São Paulo, SBG. p.127-134.

CORDANI, U.G.; BRITO NEVES, B.B. (1982) The geologic evolution of South America during the Archaean and Early Proterozoic. Revista Brasileira de Geociências, v. $12, \mathrm{n} .1-3, \mathrm{p} .78-88$. 
CORDANI, U.G.; TEIXEIRA, W. (1979) Comentários sobre as determinações geocronológicas existentes para as regióes das folhas Rio de Janeiro, Vitória e Iguape. In: CARTA GEOLÓGICA DO BRASIL AO MILIONÉSIMO; Folhas Rio de Janeiro (SF.23), Vitória (SF.24) e Iguape (SG.23). Brasília, DNPM. p.175. 207.

EBERT, H. (1956) Tectônica do PréCambriano (São João Del Rey). Relatório Anual do Diretor. DGM/ DNPM, n.1955, p.62-81.

EBERT, H. (1957) A tectônica do sul do Estado de Minas Gerais e regiões adjacentes. Relatório Anual do Diretor. DGMDNPM, n.1956, p.97107.

EBERT, H. (1968) Ocorrência de fácies granulítica no sul de Minas Gerais e regiões adjacentes, em dependência da estrutura orogênica: hipótese sobre a sua origem. Anais da Academia brasileira de Ciências, Supl. v. 40, p. $215-229$.

EBERT, H. (1971) Os Paraibídes entre São Joăo Del Rey, Minas Gerais e Itapira, São Paulo, e a bifurcação entre Paraibides e Araxaides. In: CONGRESSO BRASILEIRO DE GEOLOGIA, 1., São Paulo. p.177-178.

FERNANDES, A.J. (1991) O Complexo Embu no leste do Estado de São Paulo: contribuição ao conhecimento da litoestratigrafia e da evolução estrutural e metamórfica. São Paulo, 120p. (Dissertaçāo - Mestrado), Instituto de Geociências, Universida-de de São Paulo.

FIGUEIREDO, M.C.H.; CAMPOS NETO, M.C. (1993) Geochemistry of the Rio Doce Magmatic Arc, Southeastern Brazil. Anais da Academia brasileira de Ciências, Supl., v. 65 , n.1, p.63-81.

FONSECA, M.J.G.; SILVA, Z.C.G.; CAMPOS, D.A.; TOSATTO, P. (1979) Carta geológica do Brasil ao
Milionésimo. Folhas Rio de Janeiro (SF-23), Vitória (SF-24) e Iguape (SG.23). Brasilia, DNPM. 240p.

HASUI, Y. (1975) Geologia da Folha de São Roque. Boletim IG-USP, v.6, p.157-183.

HASUI, Y.; OLIVEIRA, M.A.F. (1984) Província Mantiqueira - setor central; In: ALMEIDA, F.F.M.; HASUI, Y. (coords.) O Pré-cambriano do Brasil. São Paulo, Edgard Blucher, p. 308-344.

HASUI, Y.; SADOWSKI, G.R. (1976) Evolução geológica do Pré-Cambriano na região sudeste do Estado de São Paulo. Revista Brasileira de Geociências, v.6, n.3, p.180-200.

HASUI, Y.; FONSECA, M.J.G.; RAMALHO, R.; COUTINHO, M.G.N. (1982) A parte central da região de dobramentos sudeste e o maciço mediano de Guaxupé. In: SCHOBBENHAUS, C.; CAMPOS, D.A.; DERZE, G.R.; ASMUS, H.E. (eds.) Geologia do Brasil: texto explicativo. Brasilia, DNPM. p.307-328.

HEILBRON, M.C.P.L. (1993) Evolução tectono-metamórfica da Seção Bom Jardim de Minas (MG)- Barra do Piraí (RJ), Setor Central da Faixa Ribeira. São Paulo, 268p. (Tese - Doutorado), Instituto de Geociências, Universidade de São Paulo.

HEILBRON, M.; VALERIANO, C.M.; ALMEIDA, J.C.H.; TUPINAMBÁ, M. (1991) A Megassinforma do Paraíba do Sul e sua implicação na compartimentação tectônica do setor central da Faixa Ribeira. In: SIMPÓSIO DE GEOLOGLA DO SUDESTE, 2., São Paulo, 1991. Atas. São Paulo, SBG. p.519-523.

KAWASHITA, K. (1972) O método $\mathrm{Rb} / \mathrm{Sr}$ em rochas sedimentares. Aplicação para as bacias do $\mathrm{Pa}$ raná e Amazonas. Sāo Paulo, 111p. (Tese - Doutorado), Instituto de Geociências, Universidade de São Paulo.

MACHADO, R. (1984) Evolução geo- 
lógica, análise estrutural e metamórfica da região de Vassouras e Paracambi, porção ocidental do Estado do Rio de Janeiro. São Paulo, 196p. (Tese - Doutorado), Instituto de Geociências, Universidade de São Paulo.

ROSIER, G.F. (1957) A geologia da Serra do Mar, entre os picos de Maria Comprida e do Desengano (Estado do Rio de Janeiro). Boletim da Divisão de Geologia e Mineralogia, v.166, p.1-58.

ROSIER, G.F. (1965) Pesquisas geológicas na parte oriental do Estado do Rio de Janeiro e na parte vizinha do Estado de Minas Gerais. Boletim da Divisão de Geologia e Mineralogia, v.222, p.1-40.

STEIGER, R.H.; JÄGER, E. (1978) Subcomission on Geochronology: convention on the use of decay constants in geo- and cosmochronology. Studies in Geology, v.6, p.67-71.

TASSINARI, C.C.G. (1988) As idades das rochas e dos eventos metamórficos da porção sudeste do Estado de São Paulo e sua evolução crustal. Sāo Paulo, 263p. (Tese - Doutorado), Instituto de Geociências, Universidade de São Paulo.

TASSINARI, C.C.G.; CAMPOS NETO, M.C. (1988) Precambrian continental crust evolution of southeastem São Paulo State - Brazil: based on isotopic evidences. Geochimica Brasiliensis, v.2, n.2, p.175-183.

TROMPETTE, R. (1994) Geology of western Gondwana (2000-500 Ma) Rotterdam, Balkema, 350p.

VALLADARES, C.S.; HEILBRON, M.; FIGUEIREDO, M.C.H. (1995) O Granito Getulândia e sua relação com a zona de cisalhamento Taxaquara. In: SIMPÓSIO NACIONAL DE ESTUDOS TECTONICOS, 5., Gramado, 1995. Boletim de Resumos Expandidos. Gramado, SBG-Núcleo RS/CPGq-UFRG. p.217-218.

C.M.Dias Neto - Instituto de Geociências, Universidade de São Paulo, Caixa Postal 11.348, CEP 05422-970, São Paulo, SP, Brasil. 